\title{
Decreased Bone Density
}

National Cancer Institute

\section{Source}

National Cancer Institute. Decreased Bone Density. NCI Thesaurus. Code C98911.

A laboratory finding indicating the presence of lower than normal bone mineral density. 